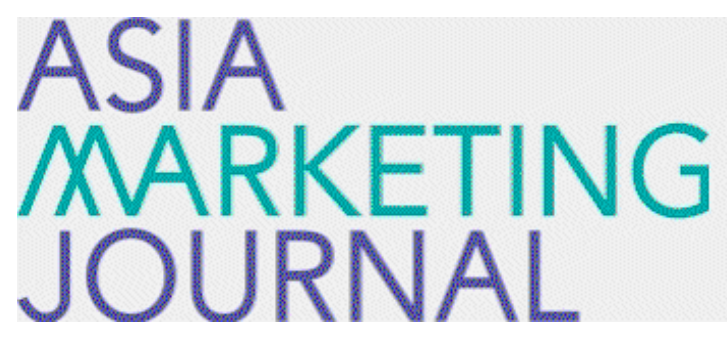

ASIA MARKETING JOURNAL

Volume 16 | Issue 1

Article 9

4-30-2014

\title{
The Effect of Perceived Risk, Hedonic Value, and Self-Construal on Attitude toward Mobile SNS
}

Ji Yoon Kim

Sang Yong Kim

Follow this and additional works at: https://amj.kma.re.kr/journal

Part of the Marketing Commons

\section{Recommended Citation}

Kim, Ji Yoon and Kim, Sang Yong (2014) "The Effect of Perceived Risk, Hedonic Value, and Self-Construal on Attitude toward Mobile SNS," Asia Marketing Journal: Vol. 16 : Iss. 1 , Article 9.

Available at: https://doi.org/10.53728/2765-6500.1532

This Article is brought to you for free and open access by Asia Marketing Journal. It has been accepted for inclusion in Asia Marketing Journal by an authorized editor of Asia Marketing Journal. 


\title{
The Effect of Perceived Risk, Hedonic Value, and Self-Construal on Attitude toward Mobile SNS
}

\author{
Ji Yoon Kim* \\ Sang Yong Kim**
}

This study investigates the effect of perceived risk on attitude toward mobile Social Network Services (SNSs). First, we understand that perceived risk of SNSs is a multidimensional concept, and we study the relationship between attitude and perceived risk such as social risk, performance risk, and privacy risk in SNS environments. Subsequently, the relationships between these multidimensional concepts of perceived risk and attitude are investigated. The result indicates that social, performance, and privacy risk have negative effects on attitude. In addition, the moderated effect of individual characteristic variables such as hedonic value and self-construal are confirmed as mitigating factors that alleviate the negative impact of perceived risk. The Findings show that customers who perceive SNSs to be risky are more likely to have a negative attitude toward SNSs. However, the negative impact of perceived risk on their attitude toward SNSs is alleviated in customers with high hedonic value. Similarly, the negative impact of perceived risk on their attitude toward SNS is weaker with customers in interdependent self-construal.

This paper presents effective segmentation variables, such as consumer's motivation (hedonic value) and psychological variable (self-construal), which mitigate the risk perception of customers. Therefore, it provides practical guidelines for the marketing managers in terms of who to target and what kind of strategies to implement in terms of these segmentation variables to approach consumers more efficiently.

Key words: Mobile SNSs, perceived risk, hedonic value, self-construal

\footnotetext{
* Adjunct Professor, Sungkyunkwan University and Post-doctoral research fellow at Pusan National University (jiyoon77@korea.ac.kr)

** Professor, Korea University Business School(sangkim@korea.ac.kr), corresponding author
} 


\section{Introduction}

A Social Network Services (SNS) is an online service that enables users to focus on so- $^{-}$ cial networks or make social interactions with others (Sledgianowski and Kulviwat 2009). They share information, interests, and talk about various issues(Uhrig et al. 2010). It has achieved great success on the Internet, as evidenced by KaKaoTalk and Facebook in Korea. This is partly due to the fact that Korea is a country with a robust high-speed internet service and is a gateway of striving to integrate globalization with social media (OECD 2013). As smart phones and tablets grow in popularity, we can expect that this phenomenon will continue to grow and evolve along with the explosion in SNSs where people communicate with each other and discuss various subjects (Young et al. 2010). Compared to internet SNSs, mobile SNSs have some advantages, such as convenience and immediacy, which enable users to interact with their friends more easily. These benefits may attract users to adopt mobile SNSs and encourage their usage.

However, the proliferation of mobile SNSs also brings negative effects. For instance, invasions of privacy, such as abusive comments and false rumors, are diffused via mobile SNS. Cyber-tailing by mobile SNS is also becoming a social problem (Neves and Pinheiron 2010; Ryu 2013). Recently, it has been found that we can identify the individual information easily with information posted in mobile SNS (Ryu 2013). Many users are afraid of using mobile SNSs due to the risk of privacy concern or other technical and information disclosure. Privacy concerns comprise an issue that affects the usage of mobile SNS, and it requires a coordinated and cooperative response. Therefore, mobile SNS operators are working to make sure that mobile devices remain safe as well as integral part of everyday life.

In this respect, we need to investigate the risk factor on attitude. Despite the proliferation of mobile SNSs, there is a lack of research on risk factors affecting the participation in mobile SNS activities and what segment group would be efficient for targeting.

Previous research on SNSs has mainly dealt with investigating factors affecting the adoption of SNSs(Boyd and Ellison 2008; Richter and Koch 2008; Kwon and Wen 2010; Lin and $\mathrm{Lu}$ 2011). For this reason, an in-depth analysis is required of the effect of risk on mobile SNS user's attitude and which kinds of risk are the most crucial factors for mobile SNS users; on this basis, strategies to diminish the risk perception can be developed. In addition, we suggest a targeting group for effective resource allocation in diminishing the risk.

Identifying the key factor for diminishing risk is crucial to building users' loyalty in the success of mobile SNS. In consequence, mobile SNS operators should take effective measures 
to attract and engage inactive users, as well as prevent the reverse process (of active users becoming) inactive. Addressing the risk factor properly will help mobile SNS operators understand the proper strategies to be implemented.

Therefore, this study contributes to the literature on mobile SNSs by addressing the issue of perceived risk and exploring its relation to the attitude toward the product. The results contribute to the literature on SNSs by demonstrating the effects of three sub-constructs of perceived risk on the product attitude. Moreover, the study can inform mobile SNS providers in terms of on how to manage service for continuous usage. Finally, the study offers insights for marketing managers, suggesting a useful customer segmentation group to mitigate the negative impacts of perceived risk.

\section{Theoretical Background and Hypotheses Development}

\subsection{Perceived risk in mobile SNSs}

Perceived risk refers to individual's cognitions as to the uncertainty and the possible negative outcomes contrary to the expected outcomes (Bauer 1960); it is also considered as the main obstacle to the acceptance of new product or electronics services (Featherman and Pavlou 2003). In simple terms, it is the amount of risk perceived by a consumer when considering a particular consumption decision (Cox and Rich 1964). According to the previous research on perceived risk, when the consequences of any actions contrast with the expected result, perceived risk influences the delay or change of the personal decision to a great extent (Shook 1997). When facing threats or risks, people have a tendency to reduce the perceived risk rather than to maximize perceived value (Kim and Yuan 2012; Mitchell 1999). Chaudhuri (2000) suggest that once customers become involved in the product or service, it is usual for them to be concerned about the uncertainty and possible negative consequences of their involvement.

Previous literature has addressed the issue of degree of perceived risk as an important factor in consumer attitude and behavior (Bettman 1973). Since the concept of perceived risk emerged in the marketing field, various types of risk have been identified (Antony et al. 2006: Cunningham 1967; Featherman and Pavlov 2003; Jacoby and Kaplan 1972). For example, Cunningham (1967) classified perceived risk into six categories: performance, financial, opportunity/time, safety, social, and psychological risk. Jacoby and Kaplan (1972) proposed seven types of risks: financial, performance, physical, psychological, social, time, and opportunity cost risk. Featherman and Pavlov (2003) identified six types of risk: performance, financial, privacy, time, social, psychological risk. From above literature, it is clear that perceived risk has 
been regarded as a multi-dimensional construct including economic risk, physical risk, functional risk, psychological risk, social risk (Jacoby and Kaplan 1972), privacy risk, and time risk (Featherman and Pavlou 2003).

Consumer perceptions of risks inherent in product usage have been studied for many years (Bauer 1967; Dowling and Staelin 1994), and it seems a logical contention that Consumers' perceived risk is a significant barrier for mobile SNS users. In this study, we define perceived risk as a consumer's belief about the potential uncertain negative consequences from mobile SNS usage. Three types of risk are said to be the most salient causes for concern in mobile SNS use from the previous literature( Dwyer et al. 2007; Shin 2010; Zhang 2013): social risk, performance risk, and privacy risk. Social risk is one of the dimensions in perceived risk in mobile SNS (Mizell 1998). Mobile SNS effectively decreases the information searching cost due to the uncertainty of interpersonal communication, and increases the ability to interconnect with others through the real-time feedback mechanism. Thus, many people want to participate in mobile SNS activities to strengthen affective ties, improve relationship with others, and increase recognition from others. Under the influence of friends and important acquaintances, most SNS users would seek to engage in mobile SNS use consistent with their peers' behavior (Heng 2009). However, once the preferred individual behavior does not align with the expected social identity, it may cause certain psychological pressure for the user to participate in the mobile SNS, which would affect the attitude toward mobile SNS.

Performance risk is associated with the malfunction of the product and concern that it may not meet the consumer expectations: for example the SNS product may turn out to be defective, and the system may be duplicated due to technological error or unintended duplicate clicks. SNSs also have technical problems, such as unintended update of sites and unanticipated charges. Therefore, consumers can have concern with their usage, and this anxiety would influence attitude toward SNS.

Privacy refers to the individual's ability to control their information (Westin 1968). It is very common to cause privacy risks when using mobile SNSs with personal information self-disclosure, voluntarily or involuntarily (Dinev and Hart 2006). Personal information leakage affects the safety of mobile SNSs; as a result, many consumers refuse to disclose personal information, and even give up on mobile SNS usage. Therefore, privacy concerns would affect the attitude toward mobile SNS negatively. Given these three risk types, we propose the following hypothesis:

\section{H1: Perceived risk of mobile SNS will neg- atively affect the user's attitude toward a Mobile SNS. \\ H1-1: Social risk will negatively affect the}


user's attitude toward a Mobile SNS.

H1-2: Performance risk will negatively affect the user's attitude toward a Mobile SNS.

H1-3: Privacy risk will negatively affect the user's attitude toward a Mobile SNS.

\subsection{The moderating role of hedonic value}

Attitude can be defined as "a learned predisposition to respond in a consistently favorable or unfavorable manner with respect to an object" (Fishbein and Ajzen 1975, p.6). Attitudes should be consistent over time as a learned process, and actual behavior should be consistent with attitudes. Attitudes are produced by past experiences and influenced by present behavior, such as feelings. It could exist in physical as well as mobile contexts (Lehrer et al. 2011). It also can be influenced by cognitive, affective, and conative factors (Dick and Basu 1994) and is often proposed to express an intended behavior toward the service or the company (Andreassen and Lindestad 1998).

Babin et al. (1994) proposed two types of values fundamental to understanding consumers' behavior due to their basic underlying presence across consumption phenomena (important determinants of customer attitude): the level of utilitarian and hedonic value that customers perceived (Babin et al. 1994; Overby and Lee 2006).
First of all, hedonic value is related to the spontaneous responses that are more personal and subjective (Babin et al. 1994). Hedonic values are derived more from enjoyment and fun, including entertainment, exploration, and self-expression (Chandon et al. 2000; Chaudhuri and Holbrook 2001) than from completion of tasks (Chaudhuri and Holbrook 2001; Hirschman and Holbrook 1982). The mobile SNS environment provides many interesting and highly interactive applications that appeal to many users. Users can make use of many online applications that can provide them with a virtual value to fulfill their social needs. In this circumstance, they experience a great joy in the use of mobile SNSs. They are satisfied with their social and virtual experience - in terms of uploading their photos or interesting videos, posting comments on each other's pages, blogging, viewing each other's profiles, joining virtual groups of common interests - to realize their need of interacting or sharing experiences with others.

On the other hand, utilitarian value often derived from the conscious pursuit of an intended consequence (Babin et al. 1994) and is primarily functional, instrumental, and cognitive (Chandon et al. 2000). Traditional marketers used to believe that market choices and consumer preferences were driven by utilitarian value (Arnold 2002). In the mobile SNS context, utilitarian value mostly derives from the ability to gather information and interconnect with others. For example, mobile SNS users can find an old 
friend or important information within the SNS platform. As a tool for finding an information source and communication, SNSs provide large groups of contacts to their members and allows them to easily manage and maintain their virtual life.

Gu et al.(2011) suggest that consumers using a mobile SNS not only for gathering information and communicating with others but also for satisfying the needs of interacting and sharing experience, which suggests that mobile SNS is a place where customers are driven by the motivations of both utilitarian as well as hedonic value. Previous research has proven that hedonic and utilitarian values are also found to moderate various relationships in customer behaviors (Jones et al. 2006; Sautter et al. 2004). Therefore, the present study focuses on the effect of hedonic value on the link between perceived risk and attitude.

Therefore, Consumers with high hedonic value seek to experience an mobile SNS environment, and just surfing the mobile SNS is a joy to them. They are a group of people who are less sensitive to the risk perception and focus on the adventure of the mobile SNS and the process itself. The reason for the hedonic value consumers' objective is because they enjoy the SNS process, not because they are intended to get the physical objective or completing the mission. In addition, hedonic value seeking consumers have a greater risk seeking tendency than others. Therefore, the effect of perceived risk on mobile SNS attitude is attenuated when the consumers have highly hedonic motivation. Given these considerations, we propose the following hypothesis:

\section{H2: Hedonic value moderates the relation- ship between perceived risk and atti- tude toward the Mobile SNS such that the relationship becomes weaker under high hedonic value.}

\subsection{Moderating role of self-construal}

Self-construal is defined as the perceptions of individuals' thoughts, feelings, and actions concerning the relation of the self to others and the self as distinct from others (Markus and Kitayama 1991; Lalwani and Shavitt 2009). Markus and Kitayama (1991) classified selfconstrual into two types: independent and interdependent self-construal. An independent self-construal refers to a person who perceives a clear boundary that separates the self from others and gives higher priority to personal goals than to group goals. An interdependent self-construal refers to an individual who define the self in terms of relationships to others and gives higher priority to group goals than to personal goals (Lalwani and Shavitt 2009). Independent self-construal mainly emphasizes separation and isolation from the social context, alienating the self, and emphasizing the self over the others. On the other hand, the inter- 
dependent self-construal emphasizes connectedness with the social context, and has a tendency to contact people, openness to others, and union with the society, and has a tendency to cooperate with the environment, and emphasize on others over the self (Triandis 1995). Although both independent and interdependent self-construal coexist within a given individual, they can be differentially activated as a function of context (Gardner, Gabriel, and Lee 1999; Stapel and Koomen 2001; van Baaren et al. 2003).

These self-construal have been linked to the cognitive processes that influence the judgments, values, and evaluation of event and behavior of consumers (Gardner et al. 1999; Markus and Kitayama 1991; Stapel and Koomen 2001; van Baaren, Maddux, Chartrand, de Bouter and de Bouter 2003). In line with previous literature, individuals' behavior is affected by the individual values they hold. Especially, those with independent self-construal pursue values such as independence, freedom, choosing one's own goals, living an exciting life, and being successfully self-reliant; those with interdependent self-construal support values such as belongingness, familial and societal safety, and respect for elders (Markus and Kitayama 1991). We argue that these different self-construal could activate and enhance the pursuit of distinct behavior. Our prediction is that interdependent self-construal users are a group of people who are less susceptible with risk factor since their goal is to belong to the society and maintain harmony with others. They stress the good interpersonal relationships and group memberships as their behavior is regulated by others' emotions and actions (Markus and Kitayama 1991). They emphasize fulfilling obligations to the group, and maintaining group harmony (Cross et al. 2011; Markus and Kitayama 1991). They focus more on the relationship with others, and they are socially sensitive. Even though perceived risk is high, they accept the risk for the purpose of their goal. In contrast, customers with independent self-construal are very sensitive to themselves. They ascribe importance to distinctiveness and being the same person in different situations (Cross et al. 2011; Markus and Kitayama 1991). If they perceive a risk with a product, this would typically be a crucial issue for them because it threatens their self-identity. Therefore, the influence of perceived risk on customers' attitude would be moderated through the way individuals conceive of themselves (Triandis 1989). Specifically, these relationships will be stronger in customers with independent self-construal while these will be attenuated in consumers with interdependent self-construal. From this perspective, the third hypothesis is derived:

H3: Self-construal moderates the relationship between perceived risk and attitude toward the Mobile SNS such that the relationship becomes weaker under high interdependent self-construal. 


\section{Analysis and results}

\subsection{Data}

The data were collected from undergraduate students in a marketing class at a certain university in Seoul. As mobile SNSs are very popular among young people, university students might be a representative group of mobile internet users. Thus, it is appropriate to choose university students as our sample(Heng 2009). We scrutinized all the questionnaires and excluded incomplete returns; we obtained a total of 180 completed survey questionnaires.

\subsection{Measurement Item}

The present research model includes six constructs. Each construct was measured with multiple items. All items were adapted from previous literature and revised as appropriate the purpose of this study (Straub et al. 2004). Scale items for sub construct of perceived risk were adapted from previous studies (Featherman and Pavlov 2003). Social risk is defined as a risk caused by the negative evaluation from other people using the SNS product. It includes three items, worded as follow: If I use a Mobile SNSs, it would lead to a social loss for me because my friends and relatives would think less highly of me/ If I use a Mobile SNSs, it will negatively affect the way people think of me/ If I use a Mobile SNSs, other people regard me as a strange person (Featherman and Pavlov 2003; Jacoby and Kaplan 1972).

Performance risk refers to the risk from the product itself and its functionality, which includes three items: I'm concerned that the performance of Mobile SNSs may not perform well/ Mobile SNSs may not provide a quality I expect/ I don't have knowledge about the technicality of Mobile SNSs (Jacoby and Kaplan 1972). Privacy risk is a concern for the individual security of information. It includes three items, worded as follow: Mobile SNSs will cause me to lose control over the privacy of my private information / Mobile SNSs will lead to a loss of privacy for me because my personal information would be used without my knowledge/ I'm concerned and sensitive to the disclosure of my information with using a Mobile SNSs (Featherman and Pavlov 2003; Westin 1968). The two items of hedonic value reflect the perceived positive feeling of SNS. The items were worded as follows: whether using mobile SNSs truly felt like as escape /I felt the excitement of the hunt when using Mobile SNSs (Babin et al. 1994; Gu et al. 2011). Interdependent self-construal was measured by the short version of the Self-Construal Scale (Gudykunst and Lee 2003), which includes four items: I sometimes do my own work/ It is important that I do my job better than others/ It is important that I defeat others/ It is important that I have to perform better than others. 〈Table 1〉 
〈Table 1〉 Measurement Item

\begin{tabular}{|c|c|c|}
\hline Construct & Measurement Item & Cronbach' a \\
\hline \multirow{3}{*}{ Social risk } & $\begin{array}{l}\text { If I use a XXX, it would lead to a social loss for me because my friends } \\
\text { and relatives would think less highly of me. }\end{array}$ & \multirow{3}{*}{0.895} \\
\hline & If I use a XXX, other people regard me as a strange person. & \\
\hline & If I use a XXX, it will negatively affect the way people think of me. & \\
\hline \multirow{3}{*}{$\begin{array}{l}\text { Performance } \\
\text { risk }\end{array}$} & I'm concerned that the performance of XXX may not perform well. & \multirow{3}{*}{0.854} \\
\hline & I'm concerned that the XXX may not provide a quality I expect. & \\
\hline & I'm concerned that I don't have knowledge about the technicality of XXX. & \\
\hline \multirow{3}{*}{ Privacy risk } & $\begin{array}{l}\text { XXX will cause me to lose control over the privacy of my payment } \\
\text { information. }\end{array}$ & \multirow{3}{*}{0.872} \\
\hline & $\begin{array}{l}\text { XXX would lead to a loss of privacy for me because my personal } \\
\text { information would be used without my knowledge. }\end{array}$ & \\
\hline & I'm concerned and sensitive to the use of XXX product. & \\
\hline \multirow{2}{*}{$\begin{array}{l}\text { Hedonic } \\
\text { Value }\end{array}$} & Using XXX truly felt like as escape. & \multirow{2}{*}{0.785} \\
\hline & During using XXX, I felt the excitement of the hunt. & \\
\hline \multirow{4}{*}{$\begin{array}{c}\text { Independent } \\
\text { Self- } \\
\text { construal }\end{array}$} & I sometimes do my own work. & \multirow{4}{*}{0.826} \\
\hline & It is important that I do my job better than others. & \\
\hline & It is important that I defeat others. & \\
\hline & It is important that I have to perform better than others. & \\
\hline \multirow[t]{3}{*}{ Attitude } & I'm positive to XXX & \multirow{3}{*}{0.971} \\
\hline & I have a favorable feeling toward XXX. & \\
\hline & I like XXX & \\
\hline
\end{tabular}

indicates the details of scale of measurement items. All items are measured using a 7-point Likert-type scale with answer choices ranging from "strongly disagree" (1) to (7) "strongly agree."

\subsection{Reliabilities and Validities test}

The reliability of each subscale was evaluated using Cronbach's coefficient a, which estimates how much each item functions as a parallel, though correlated, test of the under- lying construct. Cronbach's a ranges from 0 (items completely uncorrelated, all variance is random) to 1 (each item yields identical information), with the convention of .70 indicating a minimally reliable subscale. The subscales included in our study all reported adequateto-good internal consistency. Validity is tested by principal component analysis. Data were analysed using SPSS18.0, and results show that $\mathrm{KMO}$ value is 0.762 , and significance probability value of Bartlett's sphericity statistical test is 0.000 , which indicates the exploratory 
factor analysis (EFA) is feasible. We used exploratory factor analysis to determine whether items across subscales related to sub-dimensions within the attribute. The EFA shows that measurement items are classified into six factors. Results of an exploratory factor analysis for items in subscales from six different instruments assessing accessibility are presented in $\langle$ Table 2〉.

\subsection{Hypothesis Testing}

\subsubsection{Regression Analysis}

Before we test the hypothesis, we calculated
Pearson correlations among the subscale scores.

Pearson correlation coefficients indicate $\mathrm{ex}^{-}$ pected relationships observed in factor analysis. We observed that the perceived risk subscale correlated negatively with attitude. Independent self-construal has no correlation with a hedonic value, as shown in 〈Table 3$\rangle$.

We regressed the three sub-construct of perceived risk on the attitude toward SNS to examine the effect of risk on attitude. As shown in 〈Table 4〉, three sub-construct of perceived risk (social, private, privacy risk) significantly affect the attitude toward mobile SNS. In addition, social risk is the most influential factor, while performance risk is the least.

〈Table 2〉 Factor Analysis of Variables

\begin{tabular}{|c|c|c|c|c|c|c|c|}
\hline Variable & Communalities & factor1 & factor2 & factor3 & factor4 & factor5 & factor6 \\
\hline Performance risk1 & 0.825 & 0.882 & & & & & \\
\hline Performance risk2 & 0.761 & 0.867 & & & & & \\
\hline Performance risk3 & 0.715 & 0.837 & & & & & \\
\hline Independent self1 & 0.752 & & 0.851 & & & & \\
\hline Independent self2 & 0.701 & & 0.821 & & & & \\
\hline Independent self3 & 0.749 & & 0.784 & & & & \\
\hline Independent self4 & 0.671 & & 0.751 & & & & \\
\hline Privacy risk1 & 0.892 & & & 0.935 & & & \\
\hline Privacy risk2 & 0.883 & & & 0.931 & & & \\
\hline Privacy risk3 & 0.742 & & & 0.808 & & & \\
\hline Social risk1 & 0.901 & & & & 0.914 & & \\
\hline Social risk2 & 0.862 & & & & 0.891 & & \\
\hline Social risk3 & 0.711 & & & & 0.801 & & \\
\hline Hedonic value1 & 0.818 & & & & & 0.891 & \\
\hline Hedonic value2 & 0.799 & & & & & 0.841 & \\
\hline Attitude1 & 0.886 & & & & & & 0.911 \\
\hline Attitude2 & 0.897 & & & & & & 0.923 \\
\hline Attitude3 & 0.849 & & & & & & 0.901 \\
\hline
\end{tabular}


〈Table 3〉 Correlation Matrix

\begin{tabular}{|c|c|c|c|c|c|c|c|}
\hline & & 1 & 2 & 3 & 4 & 5 & 6 \\
\hline 1 & Social Risk & 1.00 & & & & & \\
\hline 2 & Performance Risk & $.168\left(^{*}\right)$ & 1.00 & & & & \\
\hline 3 & Privacy Risk & 0.110 & $.165\left(^{*}\right)$ & 1.00 & & & \\
\hline 4 & Attitude & $-.219(* *)$ & $-.191(* *)$ & $-.329(* *)$ & 1.00 & & \\
\hline 5 & Independent self-construal & 0.07 & -0.04 & -0.12 & $.217(* *)$ & 1.00 & \\
\hline 6 & Hedonic Value & $.261(* *)$ & 0.04 & $-.263(* *)$ & $.327(* *)$ & -0.08 & 1.00 \\
\hline
\end{tabular}

〈Table 4〉 Multiple Regression Analysis Result

\begin{tabular}{cccccccc}
\hline \multirow{2}{*}{ Model } & \multicolumn{2}{c}{ Non standiadized } & Standardized & \multirow{2}{c}{ P-value } & \multicolumn{2}{c}{ Collinearity statistics } \\
& $\mathrm{B}$ & $\mathrm{SD}$ & $\beta$ & & & tolerance & VIF \\
\hline constant & 6.015 & 0.34 & & 17.67 & .000 & & \\
Social Risk & -0.381 & 0.093 & -0.263 & -4.093 & .000 & 0.954 & 1.048 \\
Performance Risk & -0.265 & 0.074 & -0.228 & -3.564 & .000 & 0.963 & 1.038 \\
Privacy Risk & -0.288 & 0.058 & -0.313 & -4.922 & .000 & 0.973 & 1.028 \\
\hline
\end{tabular}

\subsubsection{Moderated regression analysis}

To test the main and interactive effects of the predictor variables, two sets of hierarchical moderated regression are used. Moderated regression is used when the moderating variable is continuous variable. As such, interaction effects are found to be significant only if the test of the increment in $R^{2}$ is statistically significant. In moderated regression, analysis of significance of interaction effects is statistically tested by regressing the dependent variable on two or more main variables (one being the independent variable, the other the hypothesized moderator variable) and the interaction of these variables (Sharma, Durand, and Gur-Arie 1981).
The form of the moderated regression equation in this research is $Y=a+b X+c Z+d X Z$, where $\mathrm{Y}$ is the dependent variable (attitude toward mobile SNSs), $\mathrm{X}$ is a independent variable (perceived risk), $Z$ is a moderator variable (hedonic value), and $\mathrm{XZ}$ is an interaction term.

〈Table 5〉 illustrates the results of the moderated regression analyses of hedonic value. $\mathrm{H} 2$ proposes that hedonic value moderates the relationship between perceived risk and attitude toward mobile SNSs. In the case of social risk, it shows that the interaction term of social risk and hedonic value is positive and marginally significant $(B=.106 ; p<.07)$. Further examination of the interaction effects indicates that the relationship between social risk and 
〈Table 5〉 Moderating effect of Hedonic Value

\begin{tabular}{|c|c|c|c|c|c|c|c|}
\hline Model & Independent Variable & $\mathrm{R}^{2}$ & $\Delta \mathrm{R}^{2}$ & Beta & t & $\mathrm{p}$-value & $\mathrm{F}$ \\
\hline 1 & Social Risk & 0.067 & - & -0.388 & -3.968 & 0.000 & $15.7^{* * *}$ \\
\hline \multirow{2}{*}{2} & Social Risk & \multirow{2}{*}{0.248} & \multirow{2}{*}{$0.18^{* * *}$} & -0.575 & -6.231 & 0.000 & \multirow{2}{*}{$33.5^{* * *}$} \\
\hline & Hedonic Value & & & 0.497 & 6.906 & 0.000 & \\
\hline \multirow{3}{*}{3} & Social Risk & \multirow{3}{*}{0.260} & \multirow{3}{*}{$0.01^{* *}$} & -0.571 & -6.21 & 0.000 & \multirow{3}{*}{$23.6^{* * *}$} \\
\hline & Hedonic Value & & & 0.217 & 1.252 & 0.212 & \\
\hline & SR*HV & & & 0.106 & 1.767 & 0.079 & \\
\hline 1 & Performance Risk & 0.017 & - & "-0.174 & -0.149 & 0.032 & $4.64^{* *}$ \\
\hline \multirow{2}{*}{2} & Performance Risk & \multirow{2}{*}{0.121} & \multirow{2}{*}{$0.10^{* * *}$} & -0.148 & -1.926 & 0.056 & \multirow{2}{*}{$13.9^{* * *}$} \\
\hline & Hedonic Value & & & 0.355 & 4.763 & 0.000 & \\
\hline \multirow{3}{*}{3} & Performance Risk & \multirow{3}{*}{0.144} & \multirow{3}{*}{$0.02 * *$} & -0.113 & -1.468 & 0.144 & \multirow{3}{*}{$11.3^{* * *}$} \\
\hline & Hedonic Value & & & 0.755 & 4.077 & 0.000 & \\
\hline & PFR*HV & & & 0.133 & 2.353 & 0.021 & \\
\hline 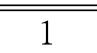 & " Privacy Risk & 0.102 & - & -0.300 & -4.929 & 0.000 & $24.3^{* * * *}$ \\
\hline \multirow{2}{*}{2} & Privacy Risk & \multirow{2}{*}{0.185} & \multirow{2}{*}{$0.08^{* * *}$} & -0.264 & -4.48 & 0.000 & \multirow{2}{*}{$23.1^{* * *}$} \\
\hline & Hedonic Value & & & 0.32 & 4.426 & 0.000 & \\
\hline \multirow{3}{*}{3} & Privacy Risk & \multirow{3}{*}{0.254} & \multirow{3}{*}{$0.07^{* * *}$} & -0.136 & -2.135 & 0.034 & \multirow{3}{*}{$22.9^{* * *}$} \\
\hline & Hedonic Value & & & -0.714 & -2.857 & 0.005 & \\
\hline & PRR*HV & & & 0.237 & 4.307 & 0.000 & \\
\hline
\end{tabular}

$*: p<0.05,{ }^{* *}: p<0.01,{ }^{* * *}: p<0.001$

attitude toward mobile SNSs is weaker when hedonic value is high, as represented by the flatter slope (see Figure 1-1). In the case of performance risk, it shows that the interaction term of performance risk and hedonic value is positive and marginally significant $(B=.133$; $p<.02)$. Further examination of the interaction effects indicates that the relationship between performance risk and attitude toward mobile SNSs is weaker when hedonic value is high. The interaction term of privacy risk and hedonic value is positive and significant $(B=$ $.237 ; p<.00)$. The interaction effect confirms that the negative effect of perceived privacy risk on attitude is attenuated when hedonic value is high. Therefore, these results all support H2. The moderating effect of independent-self construal is as follows. 〈Table 6〉 shows the result of moderated regression analysis. In the case of social risk, it shows that the interaction term of social risk and independent self-construal is negative and significant $(B=-.198$; $p<.01)$. Further examination of the interaction effects indicates that the relationship between social risk and attitude toward mobile SNSs is weaker when independent self-construal is low (interdependent self-construal is high), as represented by the flatter slope (see Figure 1-2). 
〈Table 6〉 Moderating effect of Independent Self -construal

\begin{tabular}{|c|c|c|c|c|c|c|c|}
\hline Model & Independent Variable & $\mathrm{R}^{2}$ & $\Delta \mathrm{R}^{2}$ & Beta & $\mathrm{t}$ & $\mathrm{p}$-value & $F$ \\
\hline 1 & Social Risk & 0.072 & - & -0.388 & -3.968 & 0.000 & $15.7^{* * * *}$ \\
\hline \multirow{2}{*}{2} & Social Risk & \multirow{2}{*}{0.150} & \multirow{2}{*}{$0.08^{* * *}$} & -0.455 & -4.786 & 0.000 & \multirow{2}{*}{$17.9^{* * *}$} \\
\hline & Independent self construal & & & 0.338 & 4.333 & 0.000 & \\
\hline \multirow{3}{*}{3} & Social Risk & \multirow{3}{*}{0.176} & \multirow{3}{*}{$0.03^{* *}$} & -0.418 & -4.399 & 0.000 & \multirow{3}{*}{$14.4^{* * *}$} \\
\hline & Independent self construal & & & 0.715 & 4.261 & 0.000 & \\
\hline & SR*IS & & & -0.198 & -2.53 & 0.012 & \\
\hline 1 & Performance Risk & 0.022 & 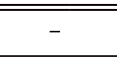 & -0.174 & -2.155 & 0.032 & $4.6^{* *}$ \\
\hline \multirow{2}{*}{2} & Performance Risk & \multirow{2}{*}{0.080} & \multirow{2}{*}{$0.06^{* * *}$} & -0.187 & -2.38 & 0.018 & \multirow{2}{*}{$8.8^{* * *}$} \\
\hline & Independent self construal & & & 0.286 & 3.571 & 0.000 & \\
\hline \multirow{3}{*}{3} & Performance Risk & \multirow{3}{*}{0.116} & \multirow{3}{*}{$0.04^{* * *}$} & -0.198 & -2.568 & 0.011 & \multirow{3}{*}{$8.8^{* * *}$} \\
\hline & Independent self construal & & & -0.134 & -0.801 & 0.424 & \\
\hline & PF*IS & & & -0.171 & -2.855 & 0.005 & \\
\hline 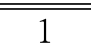 & Privacy Risk & 0.106 & - & $\begin{array}{c}-0.3 \\
\end{array}$ & -4.929 & 0.000 & $24.3^{* * * *}$ \\
\hline \multirow{2}{*}{2} & Privacy Risk & \multirow{2}{*}{0.139} & \multirow{2}{*}{$0.03^{*}$} & -0.271 & -4.461 & 0.000 & \multirow{2}{*}{$16.4^{* * *}$} \\
\hline & Independent self construal & & & 0.217 & 2.762 & 0.006 & \\
\hline \multirow{3}{*}{3} & Privacy Risk & \multirow{3}{*}{0.144} & \multirow{3}{*}{0.01} & -0.259 & -4.194 & 0.000 & \multirow{3}{*}{$11.4^{* * *}$} \\
\hline & Independent self construal & & & 0.464 & 2.011 & 0.046 & \\
\hline & PV*IS & & & -0.056 & -1.138 & 0.256 & \\
\hline
\end{tabular}

${ }^{*}: \mathrm{p}<0.05,{ }^{* *}: \mathrm{p}<0.01,{ }^{* * *}: \mathrm{p}<0.001$

In the case of performance risk, it shows that the interaction term of performance risk and Independent self-construal is negative and significant $(B=-.171 ; p<.01)$. Further exami- nation of the interaction effects indicates that the relationship between performance risk and attitude toward mobile SNSs is weaker when independent self-construal is low (interdependent
Attitude

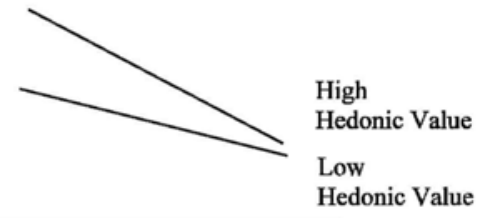

Social risk

〈Figure 1-1〉

Interaction between hedonic value and social risk on attitude

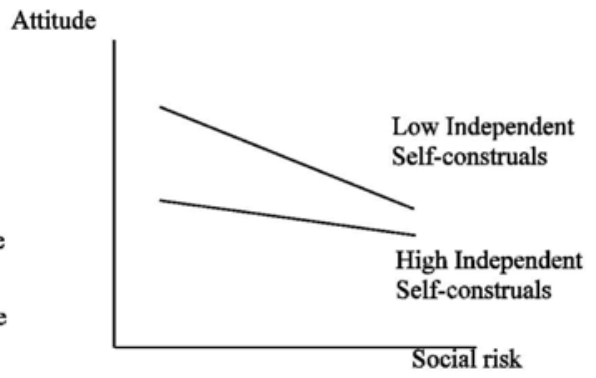

〈Figure 1-2〉

Interaction between Independent Self-

Constraual and social risk on attituede 
self-construal is high). However, the interaction effect of privacy risk and independent self-construal is not significant $(B=-.056 ; p$ $<.25)$. Therefore, H3 is partially supported.

\section{Conclusions and Implications}

This study examined the impact of perceived risk on attitude toward mobile SNSs. The empirical test of the model demonstrates that customers who perceive mobile SNSs to be risky are more likely to have a negative attitude toward mobile SNSs. In particular, privacy risk is the most influential factor to the attitude, while performance risk is the least. Moreover, it also explored hedonic value and independent self-construal as mitigating factors that alleviate the negative impact of perceived risk. We propose three important risk facets in mobile SNS environment: social risk, performance risk, and privacy risk. The negative impact of perceived risk on their attitude toward mobile SNSs is alleviated in customers with high hedonic value. Similarly, the negative impact of perceived risk on attitude toward mobile SNSs is weaker with customers in interdependent self-construal.

The majority of SNSs research focuses mainly on examining the factors affecting consumer behavior such as perceived usefulness, relative advantage, and enjoyment(Barker 2009; Lin and Lu 2011; Shin 2009; Syed-Ahmad and Murphy 2010). This research focuses on the risk facets that have been regarded as an important factor in information technology adoption(Featherman and Pavlou 2003; Peter and Ryan 1976). The present study found privacy risk to be a significant predictor of attitude toward mobile SNSs(Dinev and Hart 2006); therefore, practitioners should be aware that it is important for users to have a perception of trust concerning privacy of their information and that it is not being used, though negligence or on purpose, without any notice. Social risk is shown to be the second strongest indicator in SNS in the present study. Social risk is very important in an mobile SNSs context since many people want to participate in mobile SNSs activities to strengthen affective ties, improve relationships with others, and increase recognition from others (Heng 2009; Son and Kim 2013). Under the circumstance of influence of other people, most mobile SNS users would follow their peers behavior to come up with the trend or maintain its social ties. People live in society, where they can communicate and cooperate together. Once the preference of individual behavior is unable to meet the expected social identity, it may cause psychological pressure for the user to participate in an mobile SNSs.

From these result, mobile SNSs operators will be able to provide more targeted personalized services and privacy protection in order to help 
customers avoid risks both in fact and in perception. It also provides a more comprehensive protection in technical capabilities and policies for users to participate in mobile SNSs actively. Policy makers and regulators are seeking to create a forum in which they are encouraged to come together to discuss concerns related to mobile privacy. This will allows users to manage their personal information effectively, and such efforts and engagement have been reflected in recent initiatives, such as the US Federal Trade Commission (Page and Molina 2013). Therefore, mobile SNS s providers need to consider the risk facet when providing mobile SNSs to users. They ought to diminish the perceived risk of their mobile SNSs in order to build good user attitudes. With these measures, users' attitude can be developed and their experience can be improved, which will further enhance their loyalty towards the mobile SNSs in question.

In addition, we suggest customer segmentation variables such as consumer's motivation (hedonic motivation) and psychological variables (self-cosntruals) that mitigate the risk perception of customers. For example, firms, thus, should expect to benefit from designing marketing targeting strategies for higher hedonic value customers who use mobile SNSs to fulfill their feeling and joy, which can diminish the negative impact of perceived risk of use in mobile SNS usage. It will lead to the increase of profit by lessening the risk perception when marketing managers' targeting a group with high hedonic value promoting a mobile SNS. Consumers with interdependent self-construal are a group of people who are less susceptible to the social and performance risk. However, this segment group is not particularly affected by privacy risk. Therefore, it provides a practical guideline for the marketing managers in terms of who to target and what kind of strategies to be implemented in terms of these segmentation variables to approach consumers more efficiently. It will lead to the proper resource allocation of a firm to be prospered for a long time.

This study extends the current research of mobile SNS behavior and reexamines the relationships among perceived risk and attitude toward SNSs. However, some limitations are worth noting. First, we conducted this research in Korea, where mobile SNS is developing rapidly. Thus our results need to be generalized to other countries. Second, we selected university students as our sample. Although students represent the largest group of mobile Internet users (Heng 2009), future research needs to be conducted with other groups of people to validate a generalizability of this study. Third, other moderating variables could be incorporated in future research, such as self-efficacy or need for cognitive closure (Webster and Kruglanski 1994). Self-efficacy refers to the belief about person's ability to perform a task (Bandura 1997). As people with high self- efficacy have 
a personal confidence in their ability to understand and evaluate task successfully, they would alleviate doubts and suspicions when facing with a risk (Gangadharbatla 2008). That is, they have more knowledge and ability to cope with dangers than those with low self-efficacy. Previous literature suggests that as self-efficacy increases, the attitudes toward the object also should increase (Ajzen and Sexton 1999). Therefore, it would be expected that the attenuating effect of risk perception will be more pronounced with persons with higher levels of self-efficacy.

〈Received February 21. 2014〉

〈Revised March 20. 2014〉

〈Accepted March 24. 2014〉

\section{References}

Ajzen, I. and J. Sexton (1999), “Depth of Processing, Belief Congruence, and AttitudeBehavior Correspondence," in Dual-Process Theories in Social Psychology, S. Chaiken and Y. Trope, eds. New York: The Guilford Press, 117-138.

Andreassen, T. W. and Lindestad, B(1998), "Customer loyalty and complex services," International Journal of Service Industry Management, 9(1), 7-23.

Antony, S., Z. Lin and B. Xu(2006), "Determinants of escrow service adoption in consumer-to-consumer online auction market: an experimental study," Decision Support Systems, 42 (3), 1889-1900.

Amold, E. J., Price, L. L., Zinkhan, G.M (2002), Consumers. McGraw-Hill, New York

Babin, B. J., Darden, W. R., Griffin, M. (1994), "Work and or fun: measuring hedonic and utilitarian shopping value," Journal of Consumer Research, 20(4), 644-656.

Bandura, A. (1997). Self-efficacy: The exercise of control. New York: Freeman.

Barker, V. (2009), “Older adolescents' motivations for social network site use: The influence of gender, group identity, and collective self-esteem," Cyber psychology \& Behavior, 12, 209-213.

Bauer, R. A. (1960), "Consumer behavior as risk taking”. Dynamic marketing for a changing world.

Boyd, D. M. and Ellison, N. B. (2010), "Social network sites: Definition, history, and scholarship," IEEE Engineering Management Review, 38(3), 16.

Chandon, P., Wansink, B., and Laurent, G. (2000), “A benefit congruency framework of sales promotion effectiveness," Journal of Marketing, 64(4), 65-81

Chaudhuri, A. (2000) “A macro analysis of the relationship of product involvement and information search: the role of risk," Journal of Marketing Theory and Practice, 1-15.

Chaudhuri, A. and Holbrook, M. B. (2001), "The chain of effects from brand trust and 
brand affect to brand performance: the role of brand loyalty," Journal of Marketing, 65 (2), 81-93

Cox, Donald F. and S. Rich(1964), "Perceived risk and consumer decision-making: The case of telephone shopping," Journal of marketing research, 14(1), 187-192.

Cross, S. E., Hardin, E. E., and Gercek-Swing, B. (2011), "The what, how, why, and where of self-construal," Personality and Social Psychology Review, 15, 142-179.

Cunningham, S. (1967), “The major dimensions of perceived risk. In: D. Cox (Ed.), Risk Taking and Information Handling in Consumer Behavior. Harvard University Press, Cambridge, MA.

Dick, A. S. and Basu, K. (1994), "Customer loyalty: toward an integrated conceptual framework," Journal of the Academy of Marketing Science, 22(2), 99-113.

Dinev, T. and Hart P. (2006), "Internet privacy concerns and social awareness as determinants of intention to transact," International Journal of Electronic Commerce, 10 (2), 7-29.

Dowling, G. and Staelin, R. (1994), “A model of perceived risk and intended risk-handling activity," Journal of Consumer Research, 21, 119-134.

Dwyer, C., S. R. Hiltz, and K. Passerini (2007), "Trust and Privacy Concern Within Social Networking Sites: A Comparison of Facebook and MySpace," Proceedings of the
Thirteenth Americas Conference on Information Systems, Keystone, Colorado, August, 9-12.

Featherman, M. S. and P. A. Pavlou(2003), "Predicting E-services Adoption: A Perceived Risk Facets Perspective," International Journal of Human-Computer Studies, 59(4), 451-474.

Fishbein, M. and I. Ajzen (1975), Belief, Attitude, Intention, and Behavior: An Introduction to Theory and Research, AddisonWesley, Reading, MA,.

Gangadharbatla, H(2008), "Facebook me: Collective self-esteem, need to belong, and internetself-efficacy as predictors of the iGeneration's attitudes toward social networking sites," Journal of Interactive $A d^{-}$ vertising, 8(2), 5-15.

Gardner, W. L., Gabriel, S., and Lee, A. Y. (1999). "I" value freedom, but "we" value relationships: Self-construal priming mirrors cultural differences in judgment," Psychological Science, 10, 321-326.

Gu, R., L. B. Oh, and K. Wang (2011), "Determinants of customer loyalty for social networking sites," Exploring the grand challenges for next generation, 52, 206-212.

Gudykunst, W. B., and Lee, C. M. (2003), "Assessing the validity of self-construal scales: a response to Levine et al.," Human Communication Research, 29(2), 253-274.

Heng, Xie (2009), "Factors Influence on College Students' Intention to SNS usage," Master 
Dissertation of Zhongshan University

Hirschman, E. C., Holbrook, M. B. (1982), "Hedonic consumption: emerging concepts, methods and propositions," Journal of Marketing, 46(3), 92-101.

Jacoby, J. and Kaplan, L. (1972), "The components of perceived risk," Advances in Consumer Research, 3, 382-383.

Jones, M. A., Reynolds, K. E., Arnold, M. J. (2006), "Hedonic and utilitarian shopping value: Investigating differential effects on retail outcomes," Journal of Business Research, 59(9), 974-981.

Kim, J. Y. and Xina Yuan(2012), "The Role of Perceived Quality in New Product Adoption Process in China," Asia Marketing Journal, 14(1), 159-174.

Kwon, O. and Wen, Y. (2010), "An empirical study of the factors affecting social network service use, Computers in Human Behavior," 26(2), 254-263.

Lalwani, Ashok K. and Sharon Shavitt (2009), "The "Me" I Claim to Be: Cultural SelfConstrual Elicits Self- Presentational Goal Pursuit," Journal of Personality and Social Psychology, 97, 88-102.

Lehrer, C., I. Constantiou, and T. Hess(2011), "Examining the determinants of mobile location based services' continuance," the proceedings of International Conference on Information Systems, 4-7.

Lin, K. Y. and Lu, H.P. (2011), "Intention to Continue Using Facebook Fan Pages from the Perspective of Social Capital Theory," Behavior and Social Networking, 14(10), 565-570.

Lin, K. Y. and Lu, H. P. (2011), "Why people use social networking sites: An empirical study integrating network externalities and motivation theory," Computers in Human Behavior, 27(3), 1152-1161.

Markus, Hazel and Shinobu Kitayama (1991), "Culture and the Self: Implications for Cognition, Emotion and Motivation," $P_{S y^{-}}$ chological Review, 98(2), 224-253.

Mitchell, V. W. (1999), "Consumer perceived risk: Conceptualizations and Models," European Journal of marketing, 33(1/2), 163-95.

Mizell, L. R. (1998), Invasion of privacy, Berkley Books.

Neves, J. P. and Pinheiro, L. O. (2010), "Cyberbullying: A Sociological Approach," International Journal of Technoethics, 1(3), 24-34.

Organization for Economic Cooperation and Development report published July 2013.

Overby, J. W. and Lee, E. J.(2006), "The effects of utilitarian and hedonic online shopping value on consumer preference and intentions," Journal of Business Research, 59 (10-11), 1160-1166.

Page, M. and Maria Molina(2013),The Mobile Economy 2013, AT Kearny.

Peter, J. Pand and M. Ryan(1976), "An investigation of perceived risk at the brand level," Journal of Marketing Research, 13, 
184-188.

Richter, A. and Koch, M. (2008), "Functions of social networking services. Proc. Intl. Conf. on the Design of Cooperative Systems, Carry-le-Rouet, France. Springer.

Ryu, J. Y (2013), “ETRI Demonstrate that cyber-tailing is easy in SNS" 2013.10.13. 12:00, Money Today http://news.mt.co. kr/ mtview.php? no $=2013101115172477389 \&$ type $=\&$ sec $=$ tech $\&$ pDepth $2=$ Ttotal $\&$ page $=148$.

Sharma, S., R. M. Durand and O. Gur-Arie (1981), "Identification and analysis of Moderator variables," Journal of Marketing Research, 291-300.

Shin, D. H. (2009), "The evaluation of user experience of the virtual world in relation to extrinsic and intrinsicmotivation," International Journal of Human-Computer Interaction, 25, 530-553.

Shin, Dong-Hee(2010), "The effects of trust, security and privacy in social networking: A security-based approach to understand the pattern of adoption," Interacting with Computers , 22(5), 428-438.

Shook, D. N.(1997), Marketing management: analysis, planning, implementation, and control, Prentice Hall.

Sledgianowski, Deb and Kulviwat, Songpol (2009), "Using social network sites: The effects of playfulness, critical mass and trust in a hedonic context," Journal of Computer Information Systems, 49(4), 74-83.

Son, J. E. and Kim, H.W.(2013), "Examining
SNS Users' Citizenship Behavior: A Social Capital Perspective," PACIS 2013 Proceedings, 166.

Stapel, D. A. and W. Koomen(2001), “I, we, and the effects of others on me: how selfconstrual level moderates social comparison effects," Journal of personality and social Psychology, 80(5), 766-781.

Syed-Ahmad, S. F. and Murphy, J. (2010), "Social networking as a marketing tool: the case of a small Australian company," Journal of Hospitality Marketing and Management, 19(7), 700-716.

Triandis, H. C. (1989), "The self and social behavior in differing cultural contexts," Psychological Review, 96, 506-517.

Triandis, H. C. (1995), Individualism and collectivism. Boulder, CO Westview.

Uhrig, J. Bann, C. Williams, P. and Evans, W. D. (2010), "Social networking websites as a platform for disseminating social marketing interventions: an exploratory pilot study," Social Marketing Quarterly, 16(1), 2-20.

van Baaren, Rick B., Cris de Bouter, Ad van Knippenberg, William W. Maddux, and Tanya L. Chartrand(2003), "It takes two to mimic: behavioral consequences of selfconstrual," Journal of Personality and Social Psychology, 84(5), 1093-1102.

Webster, D. M. and Kruglanski, A. W. (1994), "Individual Differences in Need for Cognitive Closure," Journal of Personality and social Psychology, 67(6), 1049-1062. 
Westin, A. F.(1968), "Privacy and freedom," Washington and Lee Law Review, 25(1), 166.

Young, S., Dutta, D., and Dommety, G. (2009), "Extrapolating psychological insights from Facebook profiles: A study of religion and relationship status," Cyberpsychology and Behavior, 12(3), 347-350.
Zhang, S., H. Chen and D. Zheng (2013), "Empirical study on users' participation behavior in SNS based on theory of perceived risks and involvement degree," Service Systems and Service. 